Article

\title{
Nanoforest: Polyaniline Nanotubes Modified with Carbon Nano-Onions as a Nanocomposite Material for Easy-to-Miniaturize High-Performance Solid-State Supercapacitors
}

\author{
Piotr Olejnik ${ }^{1,2, *}$, Marianna Gniadek ${ }^{2}\left(\mathbb{D}\right.$, Luis Echegoyen ${ }^{3}$ and \\ Marta E. Plonska-Brzezinska ${ }^{4, *(D)}$ \\ 1 Institute of Chemistry, University of Bialystok, Ciolkowskiego 1K, 15-245 Bialystok, Poland \\ 2 Department of Chemistry, University of Warsaw, Pasteur 1, 02-093 Warsaw, Poland; \\ mgniadek@chem.uw.edu.pl \\ 3 Department of Chemistry, University of Texas at El Paso, 500 W. University Ave., El Paso, TX 79968, USA; \\ echegoyen@utep.edu \\ 4 Faculty of Pharmacy with the Division of Laboratory Medicine, Medical University of Bialystok, \\ Mickiewicza 2D, 15-222 Bialystok, Poland \\ * Correspondence: polejnik@chem.uw.edu.pl (P.O.); marta.plonska-brzezinska@umb.edu.pl (M.E.P.-B.)
}

Received: 11 November 2018; Accepted: 14 December 2018; Published: 19 December 2018

check for updates

\begin{abstract}
This article describes a facile low-cost synthesis of polyaniline nanotube (PANI $\mathrm{NT})$-carbon nano-onion (CNO) composites for solid-state supercapacitors. Scanning electron microscopic (SEM) analyses indicate a uniform and ordered composition for the conducting polymer nanotubes immobilized on a thin gold film. The obtained nanocomposites exhibit a brush-like architecture with a specific capacitance of $946 \mathrm{~F} \mathrm{~g}^{-1}$ at a scan rate of $1 \mathrm{mV} \mathrm{s}^{-1}$. In addition, the nanocomposites offer high conductivity and a porous and well-developed surface area. The PANI $\mathrm{NT}-\mathrm{CNO}$ nanocomposites were tested as electrodes with high potential and long-term stability for use in easy-to-miniaturize high-performance supercapacitor devices.
\end{abstract}

Keywords: polyaniline nanotube; carbon nano-onion; conducting polymer; nanocomposite

\section{Introduction}

Electronic technology has been intensively developed over the last several decades. New research trends are focused on creating novel, fast-responding, and miniaturized electronic devices. To increase the energy, semiconductors have been replaced by carbon and organic materials such as proteins, conducting polymers, or their combinations. Such combinations of at least two materials of different chemical nature are called composites [1-3]. Previous research investigated polymers containing a $\pi$-electron conjugated system in their structures, e.g., polyaniline (PANI), polythiophene, and polypyrrole. These polymers are characterized by high values of the specific conductivity, which can be controlled by the oxidation state, $\mathrm{pH}$ [4], and type of dopant ions [5]. Such flexibility, in combination with their properties, corrosion resistivity, and chemical neutrality opens up numerous possibilities for their application in electronic devices.

PANI is a pioneering representative of the conducting polymer group. The PANI chains consist of - p-coupled aniline units (Scheme 1) [6]. The combination of benzenoid and quinoid rings leads to different oxidation states for the PANI polymer: leucoemeraldine, emeraldine, and pernigraniline. Due to the presence of negative polarons, the green emeraldine form of PANI exhibits electroconductive properties. In addition to advantages such as a high conductivity of $9 \mathrm{~S} \mathrm{~cm}^{-1}$ [7], high chemical stability, 
and low-cost chemical or electrochemical preparation methods, this polymer also exhibits potential capacitive properties. The capacitance strongly depends on the chemical and physical properties of the polymer, which are frequently a consequence of the synthesis procedure.

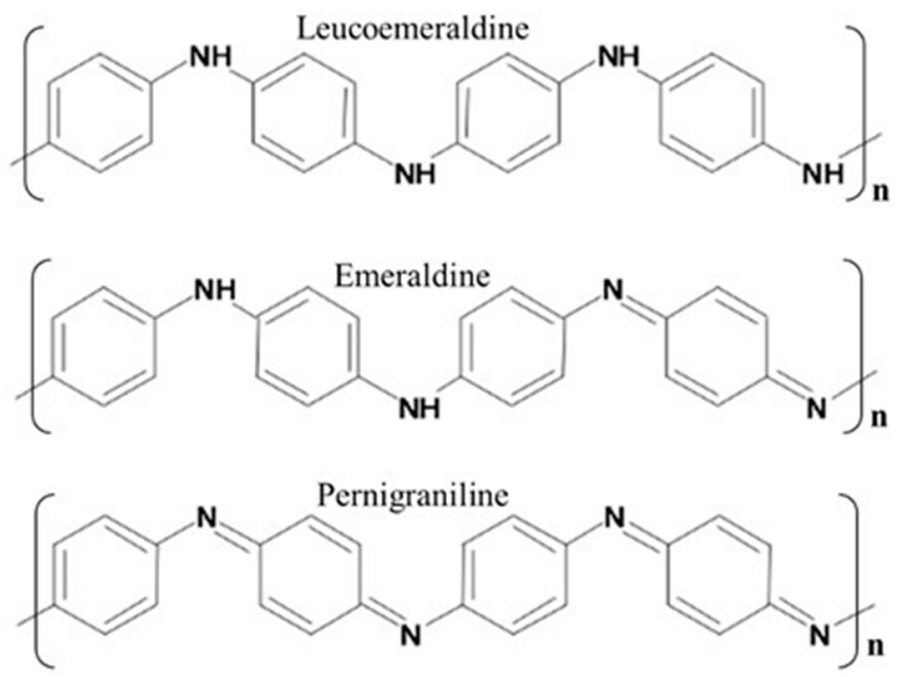

Scheme 1. Repeatable units of polyaniline (PANI) in the most common polymer forms.

The effectiveness of supercapacitors (SCs) is determined by several important material factors, including electroconductivity, type of dopant ions, specific surface area, morphology, and pore size, as well as the material arrangement, distribution, and orientation with respect to the surface [8]. In particular, morphology is a crucial parameter for solid-state devices, because it can increase the interface between an electrode and electrolyte [9]. Therefore, nanostructured conducting polymers have received attention due to their high surface area-to-volume ratio and high surface free energy [10]. There are several synthetic pathways for aniline oxidation and different types of nanostructure production, which lead to the formation of different phases for PANI. The most popular methods are chemical oxidation [11], template methods [12], and electrochemical processes [13], with less popular methods involving sonochemical [14] or radiation approaches [15]. Dhawale et al. have reported a specific capacity of $503 \mathrm{~F} \mathrm{~g}^{-1}$ for bulk PANI synthesized via a chemical bath deposition method

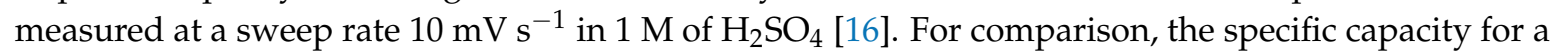
PANI nanofiber-modified electrode obtained in the same acid solution in the presence of an ammonium persulfate oxidant, was determined to be $235 \mathrm{~F} \mathrm{~g}^{-1}$ [17]. The above-mentioned methods enable one to realize randomly aggregated granules, nanoroughened polymer hydrophobic surfaces, nanospheres surrounded by surfactant molecules, nanofibers, or nanotubes inside the membrane matrix [18].

One of the most common techniques for the formation of polymer nanostructures is template synthesis, which is often used in the controlled fabrication of PANI nanotubes (PANI $\mathrm{PT}_{\mathrm{NT}}$ ) 12,19$]$. Template selection enables control over the nanotube length and its internal cavity diameter, which consequently affects the nanostructure's properties. The mechanism for nanotube formation is based on the aniline nucleating a stacking process, which is stabilized by $\pi-\pi$ interactions between phenazine structures [20]. Due to the strong intermolecular interaction between polymer chains, $\mathrm{PANI}_{\mathrm{NT}}$ reveals high conductivity relative to bulk polymer films [21-23]. Martin et al. confirmed experimentally that the conductivity for randomly distributed $\mathrm{PANI}_{\mathrm{NT}}$ depends on the nanotube size, and is six times higher than that of the macromolecular polymer [7]. Therefore, the electric properties for nanostructures (conductivity and capacity) can be enhanced by increasing the degree of material order [24,25]. In the case of $\mathrm{PANI}_{\mathrm{NT}}$, the most effective ordering occurs for nanostructures that are oriented perpendicular to the surface. Such arrangement enables easier internal and external nanotube modification, which can significantly increase the total specific surface area, which is the 
most important parameter in the SC field $[26,27]$. PANI $\mathrm{NT}_{\mathrm{N}}$ are also only slightly soluble in common organic solvents, which is crucial for chemical stability.

Despite the many advantages of conducting polymers, they also exhibit certain disadvantages that limit the polymers' practical use in SCs. For example, these polymers cannot be utilized on their own as SC electrodes due to a poor power density, low charge exchange rates, and poor long-term stability during the charge-discharge processes, which lead to electrode damage [28]. To overcome these disadvantages, composite materials are frequently used as electrodes for SCs. Material systems often used as electrodes in SCs are carbon nanomaterials (CNs) and conducting polymers. Combining conducting polymers with CNs mainly enhances the specific surface area, inducing high porosity, facilitating electron and proton conduction, increasing the number of active sites, protecting active materials from mechanical degradation, and improving cycling stability [29-32]. PANI composites with CNs, such as single-walled carbon nanotubes (SWCNTs), multi-walled carbon nanotubes (MWCNTs) or graphene $(\mathrm{G})$ and graphene oxide $(\mathrm{GO})$ sheets, have been reported. The specific capacitance for the above listed PANI/carbon nanocomposites are: $485 \mathrm{~F} \mathrm{~g}^{-1}, 560 \mathrm{~F} \mathrm{~g}^{-1}, 413 \mathrm{~F} \mathrm{~g}^{-1}$, and $375 \mathrm{~F} \mathrm{~g}^{-1}$, respectively [33-36].

In this report, we focus on the synthesis of a composite containing $\mathrm{PANI}_{\mathrm{NT}}$ and multilayered fullerenes, frequently called as carbon nano-onions (CNOs). CNOs consist of a hollow spherical fullerene core surrounded by concentric and curved graphene layers with progressively increasing diameters. The interlayer distance between neighboring layers is $0.335 \mathrm{~nm}[37,38]$. These CNOs can have different sizes and shapes, which, in turn, determine their physical properties and chemical reactivity [39-42]. In our study, we used small spherical CNOs obtained by the graphitization of nanodiamond particles (NDs, $5 \mathrm{~nm}$ ) at high temperature under partial vacuum [42,43]. These CNOs show the unique combination of mechanical properties with chemical and physical properties [44,45]. They possess a relatively high surface-to-volume ratio, high conductivity, and high thermal stability. These properties, with the combination of satisfactory compatibility, can lead to the preparation of composite materials. Their high reactivity when compared with CNs enables one to create homogeneous three-dimensional (3D) composite materials using both organic and inorganic components [45-48]. The reactivity of fullerene-like structures, including CNOs, decreases with increasing size due to a decrease in the curvature of the surface, due to decreased strain. Additionally, the ability to functionalize CNO surfaces depends on the presence of defects on the carbon surface as well as on the presence of carbon atoms with $s p^{2}$ hybridization. The integration of CNOs with other substances can lead to interesting materials possessing properties of the individual components. In particular, the combination of CNOs with conducting polymers yields new materials [29-32], which are highly attractive as electrode materials for electrochemical and biomedical purposes. We have already emphasized that the organization of the two components in the matrix, and the scale on which this occurs, have a decisive influence on the physicochemical properties of the synthesized materials.

\section{Materials and Methods}

\subsection{Materials}

Aniline monomer and sulfuric acid $95-97 \%$ were purchased from POCh (Gliwice, Poland). Ammonium persulfate $98 \%\left(\mathrm{NH}_{4}\right)_{2} \mathrm{~S}_{2} \mathrm{O}_{8}, \mathrm{~N}$-hydroxysuccinimide (NHS), and 1-ethyl-3-(3-dimethyl aminopropyl) carbodiimide hydrochloride (EDC) were purchased from Sigma Aldrich (Saint Louis, Missouri, USA) and used as received. Chloroform was obtained from Chempur (Piekary Slaskie, Poland). Aluminum oxide powder was purchased from Buehler Micropolish (Esslingen, Germany). All of the reagents (p.a. grade) were used without further purification. All of the solutions were prepared using water purified by a Milli-Q system from Merck (Darmstadt, Germany) with a resistivity of $18.2 \mathrm{M} \Omega$ and $\mathrm{pH}$ of 7 . 


\subsection{Polyaniline Nanotube Matrix Synthesis}

PANI $_{N T}$ synthesis was accomplished by the template method. Whatman Nuclepore polycarbonate (PC) membranes (with diameter $200 \mathrm{~nm}$ ) were used as templates. The synthesis process was conducted in $1 \mathrm{M}$ of sulfuric acid medium by the chemical oxidation of the aniline monomer using ammonium persulfate as oxidant. In a typical experiment, a PC membrane was coated on one side with a thin, uniform gold film using a plasma sputter coater (Leica ACE 200, Wetzlar, Germany) by vapor deposition. The modified template was then soaked in five $\mathrm{mL}$ of $0.3 \mathrm{M}$ of aniline acidic medium for $30 \mathrm{~min}$ before being mixed with the same volume of $0.3 \mathrm{M}$ of $\left(\mathrm{NH}_{4}\right)_{2} \mathrm{~S}_{2} \mathrm{O}_{8}$ in one $\mathrm{M}$ of sulfuric acid solution. The reaction vessel was kept at a low temperature $\left(\sim 4^{\circ} \mathrm{C}\right)$. The typical reaction time was approximately three hours. Subsequently, the membrane was dissolved in chloroform and removed. Next, the separated thin gold film with $\mathrm{PANI}_{\mathrm{NT}}$ was carefully rinsed with deionized water.

\subsection{Synthesis of Pristine and Oxidized CNOs}

Pristine CNOs: Commercially available nanodiamond powder (NDs, Carbodeon $\mu$ Diamond ${ }^{\circledR}$ Molto, Vantaa, Finland) with a crystal size between four and six nm and nanodiamond content larger than $97 \mathrm{wt} \%$ ), was used for the preparation of spherical CNOs using the procedure proposed by Kuznetsov et al. [49] NDs were placed in a graphite crucible and transferred to an Astro carbonization furnace. Annealing of the ultradispersed NDs was carried out at $1650{ }^{\circ} \mathrm{C}$ under a 1.1 MPa He atmosphere using a heating rate of $20^{\circ} \mathrm{C} \mathrm{min}-1$. The final temperature was maintained for one hour; then, the material was slowly cooled to room temperature. The furnace was opened, and the $\mathrm{CNOs}$ were annealed in air at $400{ }^{\circ} \mathrm{C}$ to remove any amorphous carbon.

Oxidized CNOs $\left(\mathrm{CNOs}_{\mathrm{ox}}\right)$ : The oxidation of pristine CNOs was conducted as originally described by Lieber et al. for SWNT [50], and later applied to CNOs in our laboratory. Then, $100 \mathrm{mg}$ of pristine CNOs was dispersed by ultrasonication for $30 \mathrm{~min}$ and refluxed for $48 \mathrm{~h}$ in $3.0 \mathrm{M}$ of aqueous nitric acid. The mixture was later centrifuged for $10 \mathrm{~min}$ followed by collection of the black powder that formed in the bottom of the test tube. Then, Salzmann's protocol was applied to purify the oxidized CNOs $\left(\mathrm{CNOs}_{\mathrm{ox}}\right)$ [51]. The resulting oxidized product was stirred in $3.0 \mathrm{M}$ of $\mathrm{NaOH}$ and washed several times with distilled water until a final $\mathrm{pH}$ of 7 was reached, and then dried overnight at $110^{\circ} \mathrm{C}$.

\subsection{Methods}

The PANI nanotubes/ $\mathrm{CNOs}_{\mathrm{ox}}$ layers deposited on the electrode surface were studied using a FEI Tecnai S-3000N (Tokyo, Japan) and a Merlin (Zeiss, Germany) field-emission scanning electron microscope (SEM). The $\mathrm{CNOs}_{\mathrm{ox}}$ nanostructures were examined by a transmission electron microscope (TEM) system Libra 120 (Zeiss, Germany). A digital optical microscope HIROX KH-87000 (Tokyo, Japan) was used for the preliminary observation of the nanocomposite material morphology and arrangement.

The infrared spectra were recorded using a NICOLET IN10 MX infrared microscope (Thermo Scientific, Waltham, Massachusetts, USA). The microscope was operated mainly in reflectance mode, and the Mercury-Cadmium-Telluride (MCT) detector cooled with liquid nitrogen. The spectra were collected for a $100-\mu \mathrm{m}$ (area $0.01 \mathrm{~mm}^{2}$ ) square region of the sample. For typical measurements, the spectral resolution was $4 \mathrm{~cm}^{-1}$, and 256 scans were averaged to obtain a single spectrum. The spectrum of the pristine $\mathrm{CNOs}_{\mathrm{ox}}$ was recorded in a potassium bromide $(\mathrm{KBr})$ pellet using the microscope in transmission mode. Additionally, the above-mentioned MCT detector was utilized for mapping the nanostructural layers.

The Raman experiments were carried out using a Renishaw Raman InVia Microscope (Wotton-under-Edge, United Kingdom) equipped with a high-sensitivity ultralow-noise Charge Coupled Device (CCD) detector. The Raman module was equipped with a microstage that enabled the measurement of a sample in reflectance mode. The instrument was operated using an Ar ion laser 
with the 514-nm excitation line. For typical measurements, the spectral resolution was $4 \mathrm{~cm}^{-1}$, with three scans (each of 10-s duration) averaged to obtain a single spectrum.

The electrochemical experiments were carried out using an AUTOLAB (Utrecht, The Netherlands) potentiostat/galvanostat with the NOVA software from AUTOLAB (Utrecht, The Netherlands). A typical three-electrode configuration was used with a glassy carbon (GC) disk electrode (two mm diameter) as the working electrode, $\mathrm{Ag} / \mathrm{AgCl}$ (with saturated $\mathrm{KCl}$ ) as the reference electrode, and a platinum mesh as the auxiliary electrode. The geometrical area of the glassy carbon electrode was equal to $0.0314 \mathrm{~cm}^{2}$. The working electrode was polished with $0.5-\mu \mathrm{m}$ alumina powder on a polishing wheel, and subsequently washed thoroughly several times with deionized water and ethanol, before being allowed to dry at room temperature. All of the measurements were performed in anaerobic conditions at room temperature $\left(22 \pm 2{ }^{\circ} \mathrm{C}\right)$. To remove all of the dissolved oxygen, the measuring cell was Ar-purged $15 \mathrm{~min}$ before the experiments began.

\section{Results and Discussion}

\subsection{Nanocomposite $P A N I_{N T} / C N O s_{o x}$ Electrode Preparation Procedure}

Schemes 2 and 3 show the simplified procedures that were used for the covalent functionalization of $\mathrm{PANI}_{\mathrm{NT}}$ with $\mathrm{CNO}_{\mathrm{ox}}$, which resulted in the creation of the nanocomposites. Briefly, the composite preparation procedure was based on two steps. In the first approach, $\mathrm{PANI}_{\mathrm{NT}}$ synthesis was accomplished by the template method described in detail in the Experimental section and schematically presented in Scheme 2. After removal of the PC membrane, the organized PANI $\mathrm{NT}_{\text {layer was formed }}$ on a gold surface.

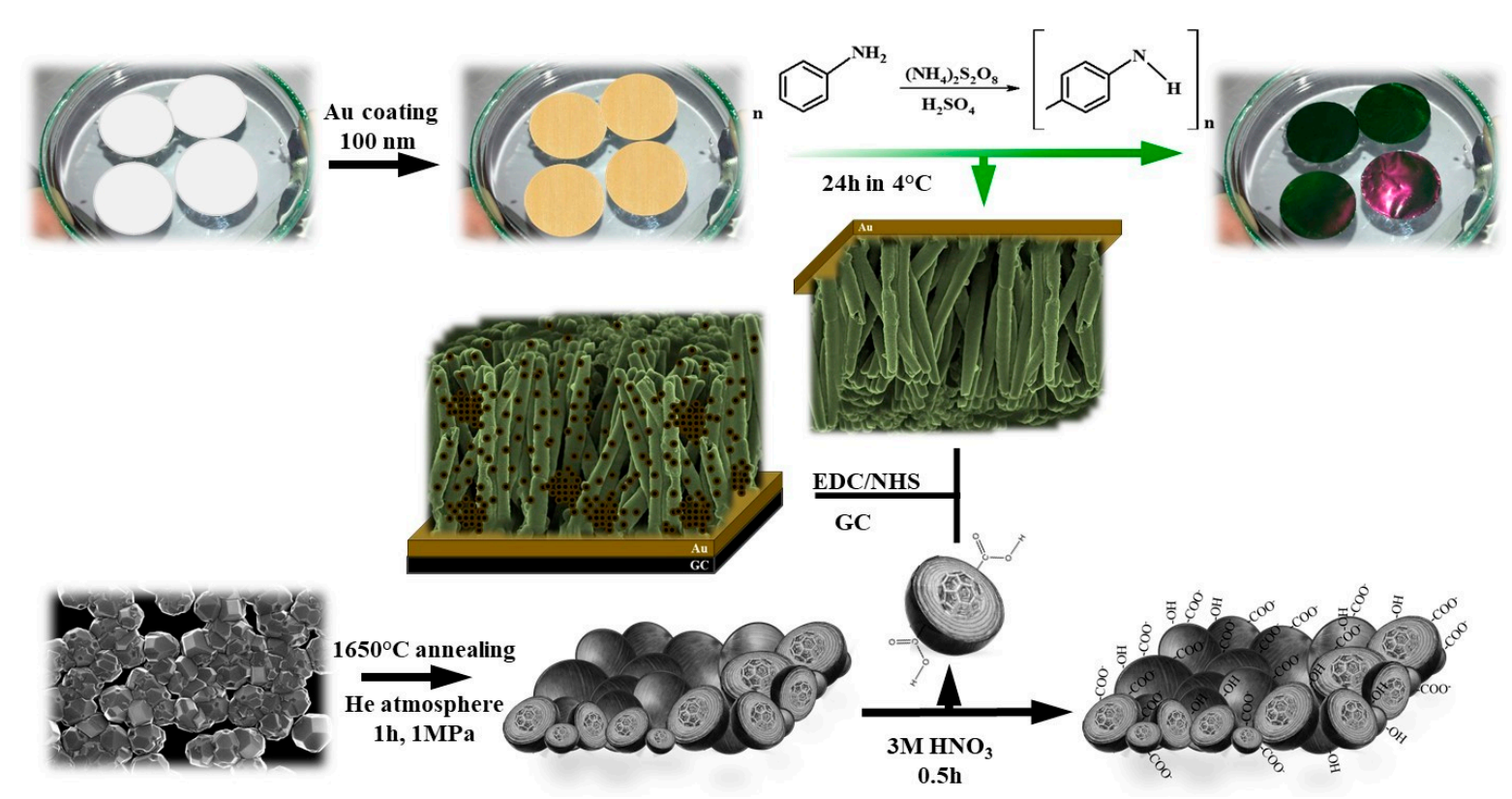

Scheme 2. Polyaniline nanotube-oxidized carbon nano-onion ( $\mathrm{PANI}_{\mathrm{NT}} / \mathrm{CNO}_{\mathrm{ox}}$ ) composite synthesis using a porous template and surface functionalization. 


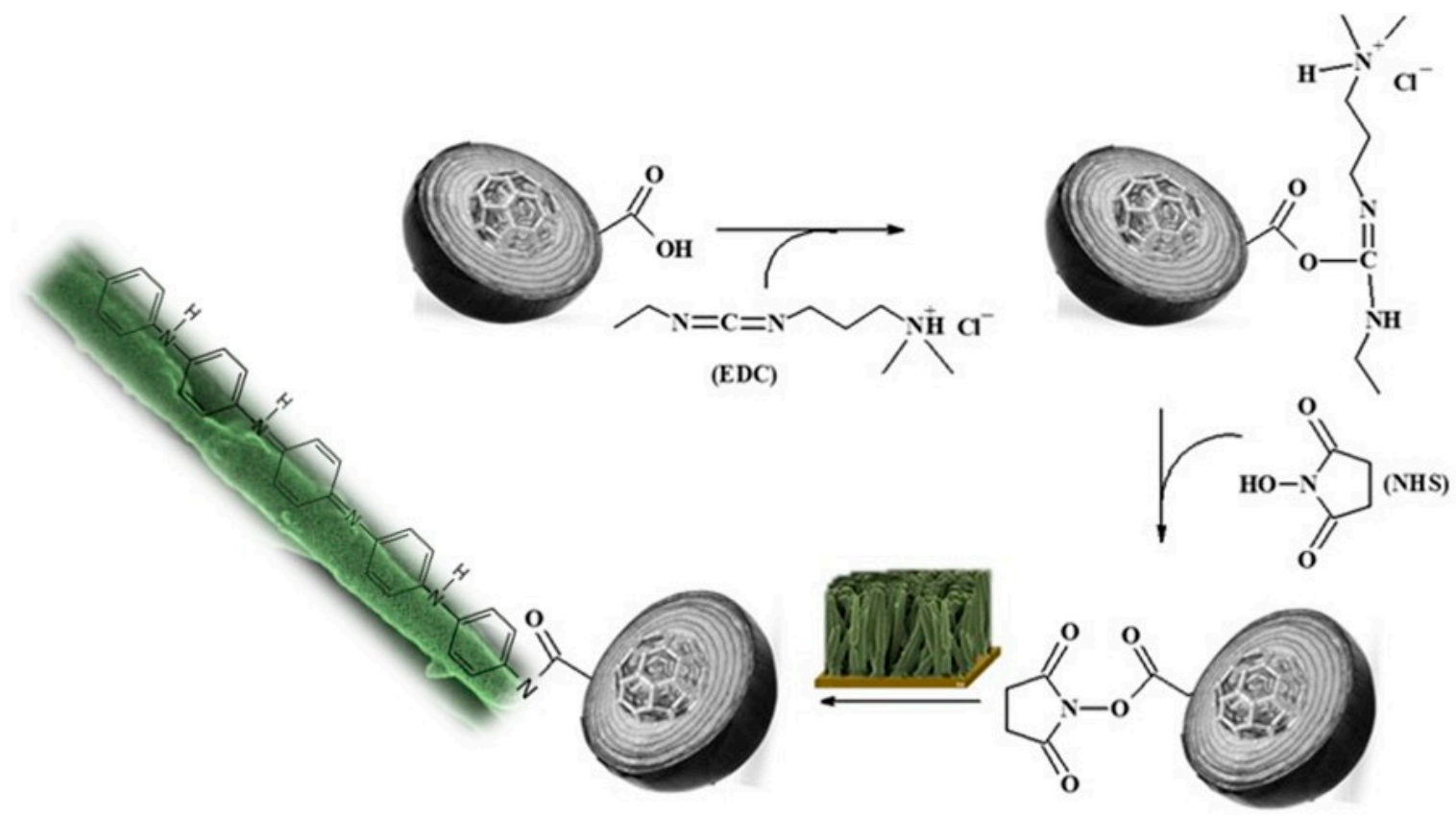

Scheme 3. The simplified procedures used for the covalent functionalization of $\mathrm{PANI}_{\mathrm{NT}}$ with $\mathrm{CNO}_{\mathrm{ox}}$.

Next, the GC electrode was repeatedly covered with an $\mathrm{Au} / \mathrm{PANI}_{\mathrm{NT}}$ nanotube film. The covalent functionalization of the $\mathrm{Au} / \mathrm{PANI}_{\mathrm{NT}}$ layers with $\mathrm{CNOs}_{\mathrm{ox}}$ was promoted via water-soluble carbodiimide (EDC) and $\mathrm{N}$-hydroxysuccinimide (NHS). This step was carried out without contact with $\mathrm{PANI}_{\mathrm{NT}}$. The procedure used was as follows: initially, one $\mathrm{mg}$ of $\mathrm{CNOs}_{\mathrm{ox}}$ was placed in a solution of $10 \mathrm{mM}$ NHS and $40 \mathrm{mM}$ EDC for one hour (Scheme 3). During this reaction, the carboxylic groups of the $\mathrm{CNOs}$ were transformed into reactive $\mathrm{N}$-hydroxysuccinimide esters. After the activation step, $\mathrm{CNOs}_{\mathrm{ox}}$ without solvent were added to one $\mathrm{mL}$ of ethanol, and the mixture was ultrasonicated for $0.5 \mathrm{~h}$ to obtain a dusky gray, uniform, and stable suspension. In the final step, the activated $\mathrm{CNO}_{\mathrm{ox}}$ suspension was transferred to the $\mathrm{Au} / \mathrm{PANI}_{\mathrm{NT}}$ surface, and after the formation of the amide bonds, the excess of unreacted carbon nanoparticles in the solution was removed from the electrode surface. The formed $\mathrm{Au} / \mathrm{PANI}_{\mathrm{NT}} / \mathrm{CNO}_{\mathrm{ox}}$ layers were tested as supercapacitors.

\subsection{Raman and Infrared Spectroscopy Studies of $P A N I_{N T} / C N O s_{o x}$}

Raman and infrared spectroscopy were utilized as the main experimental techniques for the qualitative characterization of the composite materials containing the carbon nanoparticles. Figure 1 shows the Raman spectrum of the oxidized CNOs. The spectrum was excited at a wavelength of $514 \mathrm{~nm}$. In general, the spectrum is composed of four characteristic peaks [52], which correspond to the contribution of the hexagonal mode characteristics of graphene or graphite. The most distinctive signal at approximately $1577 \mathrm{~cm}^{-1}$ is called the $G$ band, which corresponds to the in-plane optical mode of vibration for two adjacent $s p^{2}$ carbon atoms on an ideal hexagonal ring of graphite. The $G$ bandwidth depends on the amount of deformed chains and hexagonal rings. A wider $G$ band corresponds to a lower order in the structure [53]. The spectra are dominated by the $D$ band at $1340 \mathrm{~cm}^{-1}$. The presence of the $D$ band is due to defects in the carbon crystalline curved structure. The larger $D$ band intensity is connected with a higher structural disorder, which is caused by the presence of oxygen functional groups on the $\mathrm{CNOs}_{\mathrm{ox}}$ surface. Additional combined tones for the peaks are located at $2674 \mathrm{~cm}^{-1}$ (2D) and $2925 \mathrm{~cm}^{-1}(D+G)$. The $2 D$ band reflects a two-photon process engaging phonons with opposite wave vectors. 


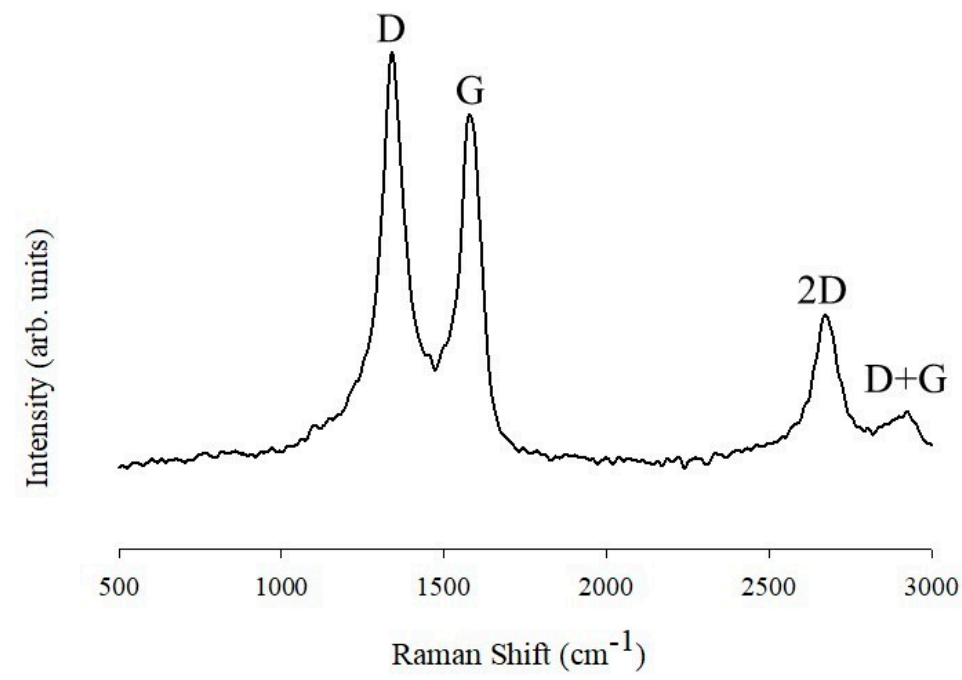

Figure 1. Raman spectrum of oxidized CNOs adsorbed on a glassy carbon electrode (GCE) surface recorded using a $514 \mathrm{~nm}$ excitation line.

Figure 2 shows the typical Raman spectra for the vertically oriented $\mathrm{PANI}_{\mathrm{NT}}$ and the $\mathrm{PANI}_{\mathrm{NT}} / \mathrm{CNOs}_{\mathrm{ox}}$ nanocomposite. The spectra were also excited at a wavelength of $514 \mathrm{~nm}$ using a $\mathrm{He}-\mathrm{Ne}$ laser. The applied excitation frequency falls in the absorption range of $\mathrm{PANI}_{\mathrm{NT}}$, thereby affecting the spectral enhancement, which is slightly shifted relative to that observed for the macromolecular form of PANI [54]. The low wavenumber region for the pristine PANI $\mathrm{NT}_{\mathrm{NT}}$ spectrum contains bands at $520 \mathrm{~cm}^{-1}$ and $814 \mathrm{~cm}^{-1}$ corresponding to $\mathrm{N}-\mathrm{H}$ and $\mathrm{C}-\mathrm{H}$ out of plane deforming vibrations of the quinonoid ring, respectively (Figure 2B). The signal at $573 \mathrm{~cm}^{-1}$ is assigned to phenoxazine and phenazine-type unit vibration $[55,56]$. The band near $1170 \mathrm{~cm}^{-1}$ is attributed to the $\mathrm{C}-\mathrm{H}$ bending vibrations for the bipolaronic, semi-quinonoid rings. This band includes a less visible shoulder at $1192 \mathrm{~cm}^{-1}$ connected with $\mathrm{C}-\mathrm{H}$ in-plane benzenoid ring bending. The signals at $1335 \mathrm{~cm}^{-1}$ and those near $1250 \mathrm{~cm}^{-1}$ are characteristic for charge carriers and correspond to delocalized polaronic units and ring deformation vibrations, respectively $[57,58]$. This indicates that the polymer nanotubes are in a conductive form. The PANI $\mathrm{NT}_{\mathrm{NT}}$ spectrum also exhibits two specific peaks: a single peak at $1496 \mathrm{~cm}^{-1}$, which is connected to the $\mathrm{C}=\mathrm{N}$ stretching mode of the quinonoid units, and double peaks in the range of $1518 \mathrm{~cm}^{-1}$ to $1620 \mathrm{~cm}^{-1}$, which provide information for the $\mathrm{C}-\mathrm{C}$ and $\mathrm{C}=\mathrm{C}$ stretching vibrations in the above-mentioned structures [59]. In the case of the $\mathrm{PANI}_{\mathrm{NT}} / \mathrm{CNOs}_{\mathrm{ox}}$ nanocomposite (Figure 2A), the spectrum confirms the presence of carbon and polyaniline nanostructures, and contains previously described characteristic signals. 


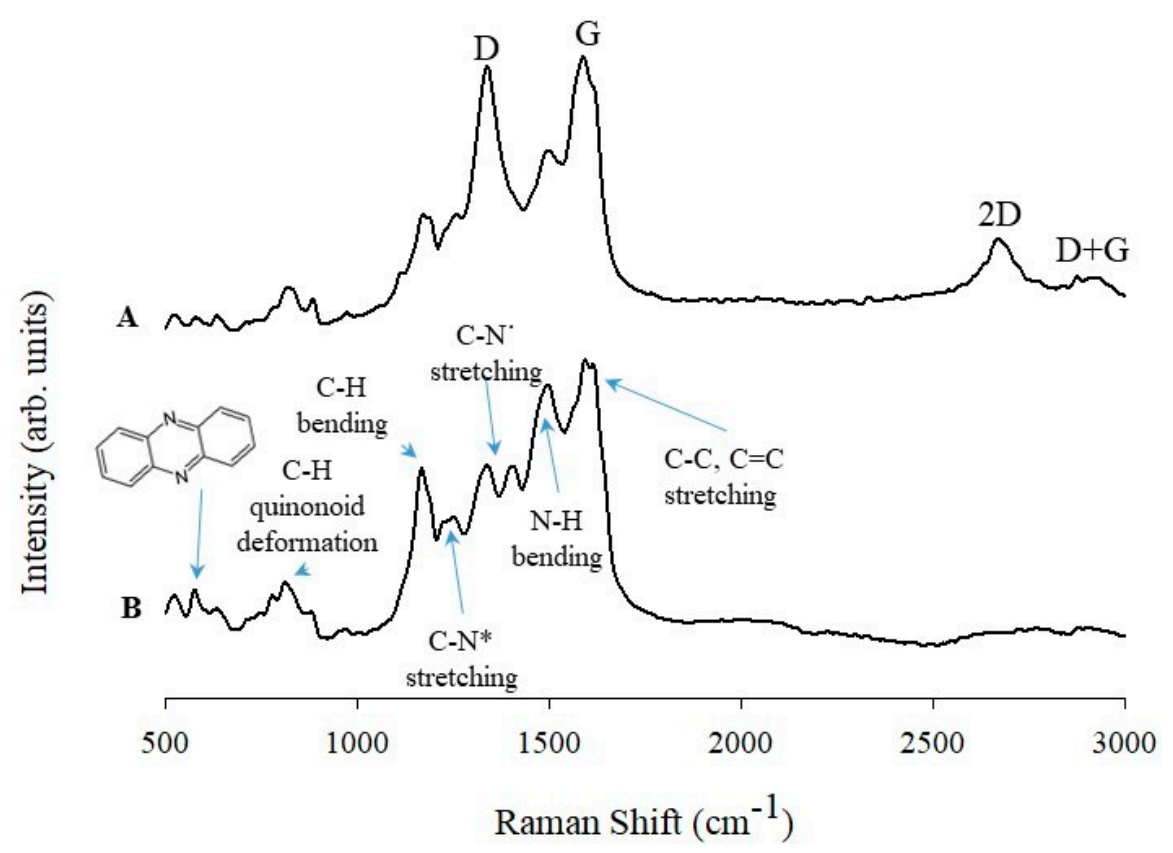

Figure 2. Raman spectra of (A) $\mathrm{PANI}_{\mathrm{NT}} / \mathrm{CNOs}_{\mathrm{ox}}$ nanocomposites immobilized on GCE/Au, and $(\mathbf{B})$ vertically oriented $\mathrm{PANI}_{\mathrm{NT}}$, recorded using excitation at $514 \mathrm{~nm}$.

The $\mathrm{PANI}_{\mathrm{NT}} / \mathrm{CNOs}_{\mathrm{ox}}$ composite was also characterized by Fourier transform infrared (FTIR), as shown in Figure 3. The nanocomposite spectrum (Figure 3A) does not differ much from that for the pristine polymer nanotubes (Figure 3B). The most typical signals are located at $837 \mathrm{~cm}^{-1}$ and $1165 \mathrm{~cm}^{-1}$, which correspond to the $\mathrm{C}-\mathrm{H}$ out-of-plane deformations and in-plane bendings in the benzene ring [60]. The peaks assigned to $1504 \mathrm{~cm}^{-1}$ and $1589 \mathrm{~cm}^{-1}$ are connected with the characteristic $C=C$ stretching vibration of the benzenoid and quinonoid rings, respectively. The bands near $1225 \mathrm{~cm}^{-1}$ and $1310 \mathrm{~cm}^{-1}$ originate from the $\mathrm{C}=\mathrm{N}$ and $\mathrm{C}-\mathrm{N}$ stretching vibrations, respectively. The broad signals at higher frequencies $\left(3000-3500 \mathrm{~cm}^{-1}\right.$ ) are connected with the free $\mathrm{N}-\mathrm{H}$ stretching vibrations $[61,62]$. The presence of $\mathrm{CNOs}_{\mathrm{ox}}$ in the composite structure is confirmed by the poorly defined peak at $1760 \mathrm{~cm}^{-1}$, which can be assigned to the carbonyl group stretching vibrations. The oxidized CNOs beyond carbonyl groups may also contain different surface functional species, including oxygen (Figure 3C) [63]. The increased intensity in the high frequency range $\left(2900-3500 \mathrm{~cm}^{-1}\right)$ could also indicate the successful functionalization of the $\mathrm{CNO}$ surface by hydroxyl groups. 


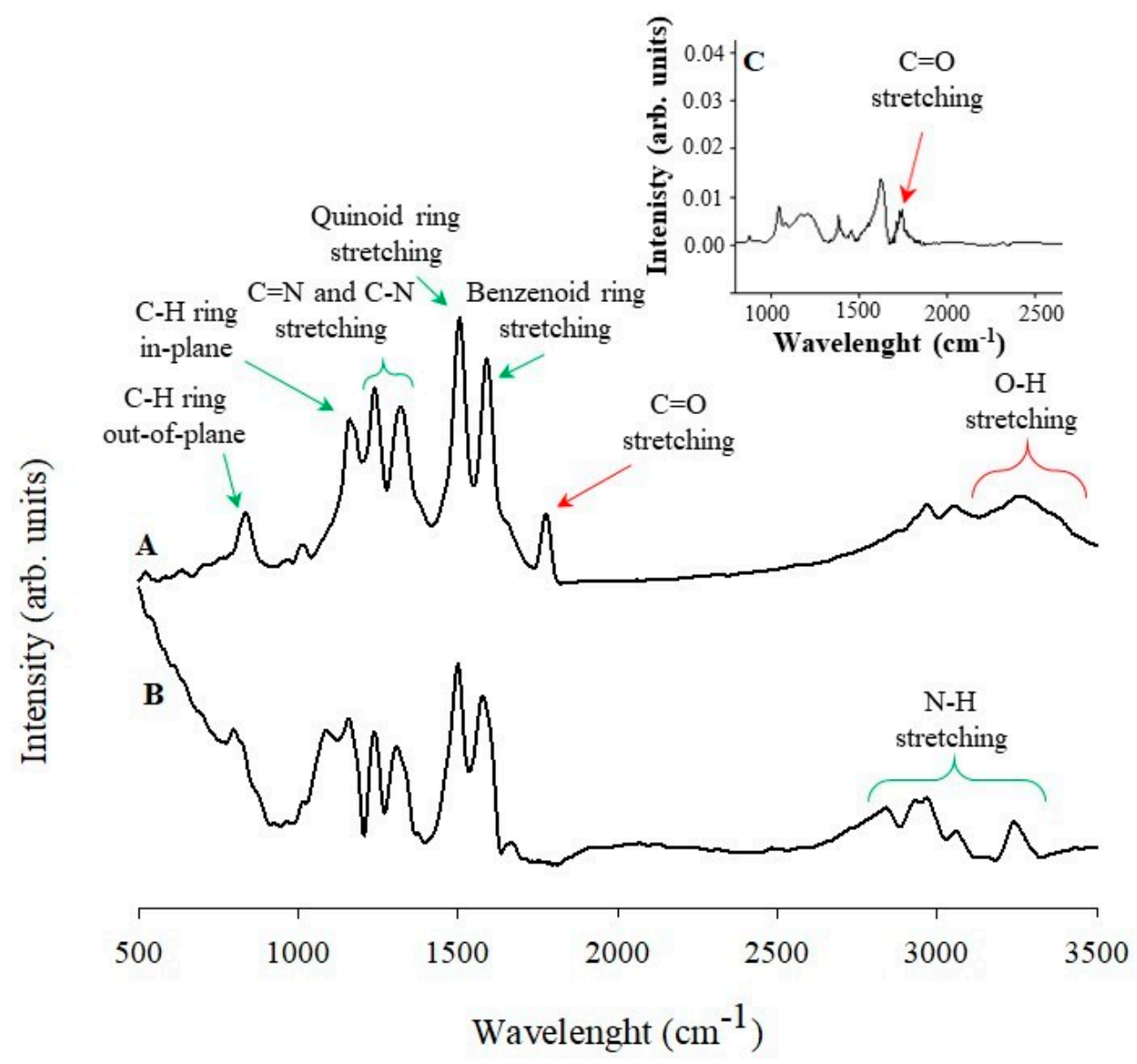

Figure 3. Infrared spectra of (A) $\mathrm{PANI}_{\mathrm{NT}}$ modified by $\mathrm{CNOs}_{\mathrm{ox}}$ immobilized on a thin gold film, (B) pure vertically formed PANI nanotubes, and $(\mathbf{C}) \mathrm{CNOs}_{\mathrm{ox}}$. Spectra recorded at room temperature using reflectance $(\mathbf{A}, \mathbf{B})$ and transmission $(\mathbf{C})$ modes.

Figure 4 shows measurements performed using an infrared mapping method. The measurement maps show the optical distribution of specific signals, with the signal intensity imaged using an appropriate color. The red color indicates the highest intensity signal or the whole spectrum. The images captured by an optical microscope reveal a large fragment of the $\mathrm{PANI}_{\mathrm{NT}} / \mathrm{CNO}_{\mathrm{ox}} / \mathrm{Au}$ surface with dimensions of $700 \mu \mathrm{m} \times 800 \mu \mathrm{m}$. A point spectrum for the nanocomposite material containing all the characteristic signals described and present in Figure 3A is shown in Figure 4D. Figure 4A illustrates the distribution profile for the $\mathrm{PANI}_{\mathrm{NT}} / \mathrm{CNOs}_{\mathrm{ox}}$ specific spectrum, and indicates the total surface coverage with a uniform nanocomposite film. A high degree of surface coverage is one of the most important parameters for electrode construction and good performance. The arrangement

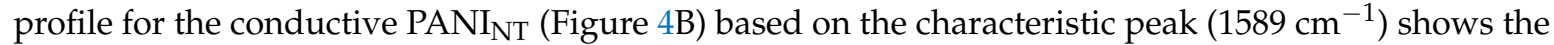
presence of nanotubes across the entire experimental area. In the case of the $\mathrm{CNOs}_{\mathrm{ox}}$, the infrared map shows more blue areas, which indicates a lower intensity for the $\mathrm{C}=\mathrm{O}$ stretching vibrations for the surface oxygen functional groups (Figure 4C). This finding reflects the small size of the CNOs and their easy aggregation. 
A

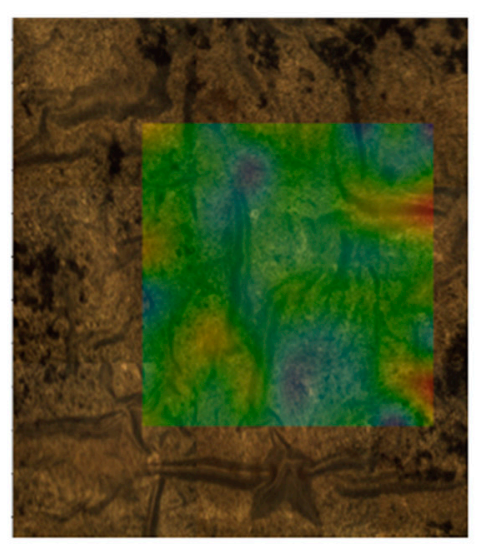

B
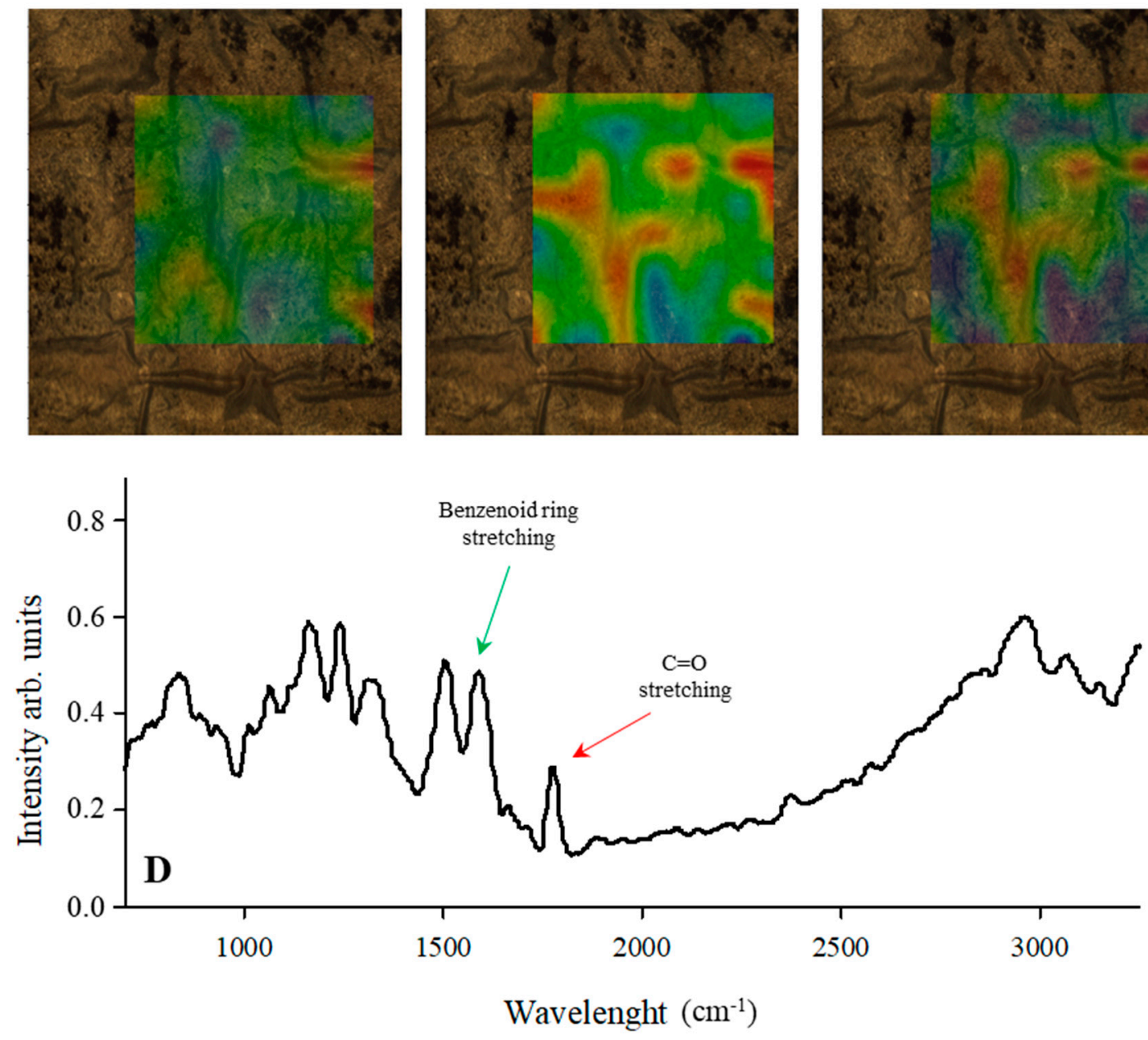

C

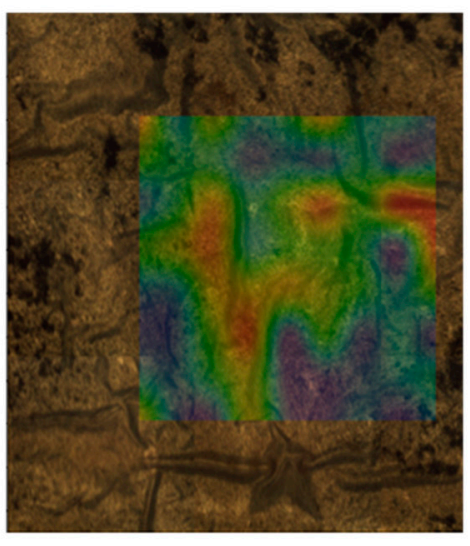

. 


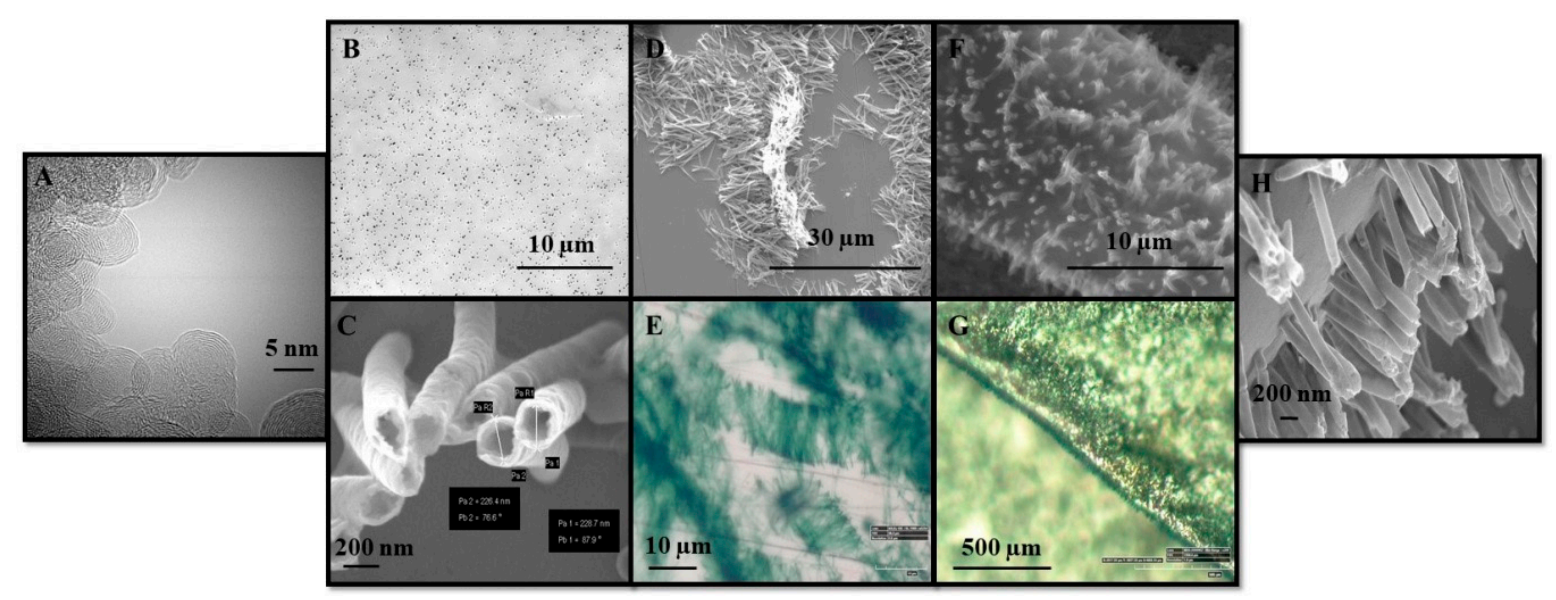

Figure 5. (A) TEM image of pristine CNOs. SEM images of a: (B) pure polycarbonate (PC) membrane surface containing unfilled pores with a diameter of $200 \mathrm{~nm},(\mathbf{C})$ empty $\mathrm{PANI}_{\mathrm{NT}}$ after the removal of the PC matrix, (D) randomly oriented $\mathrm{PANI}_{\mathrm{NT}}$ on an Au surface, $(\mathbf{F}, \mathbf{H})$ vertically oriented brush-like $\mathrm{PANI}_{\mathrm{NTs}}$ forest on $\mathrm{Au}$ film, and (E) optical microscopy images at light field mode for randomly dispersed and $(\mathrm{G})$ vertically oriented $\mathrm{PANI}_{\mathrm{NT}}$ on an Au surface.

The synthesis of conductive PANI, which was used to form nanotube structures, was accomplished by the template procedure (Scheme 2). The smooth flat surface of the PC membrane, which was used as a template, is also shown in Figure 5B. The diameter of the pore sharply defines the diameter of the polymer nanotubes, which in this case is equal to $200 \mathrm{~nm}$. The density of the pore distribution in the PC membrane reflects the amount of the $\mathrm{PANI}_{\mathrm{NT}}$ structures formed on the surface. Additionally,

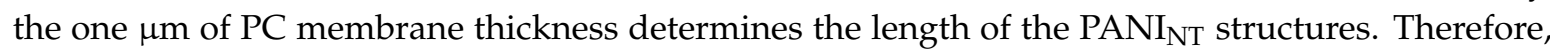
the membrane that is used defines the size of the nanotubes in three dimensions. Figure $5 \mathrm{C}$ confirmed that the nanotubes formed during the polymerization process are unfilled and empty inside. The average diameter of the polymer nanotubes is $200 \pm 30 \mathrm{~nm}$, and depends on the side-wall thickness. The $\mathrm{PANI}_{\mathrm{NT}}$ are not completely straight due to the membrane removal via repeatable steps, but they

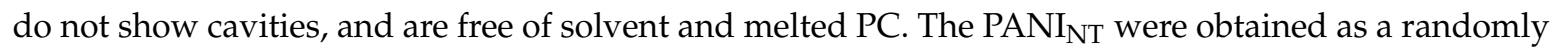
assembled nanostructure (Figure 5D,E), where chain aggregates are formed that rise vertically to the surface (Figure $5 \mathrm{~F}-\mathrm{H}$ ). The second step for the synthesis required a prior sputtering of a thin gold layer onto the membrane. The sputtered 100-nm thick gold films completely blocked the pores on one side, and became a substrate for the growth of $\mathrm{PANI}_{\mathrm{NT}}$. Figure $5 \mathrm{~F}, \mathrm{G}$ indicates that the polymer nanotubes extend perpendicularly to the surface, creating a brush-like "nanoforest". The PANI ${ }_{\mathrm{NT}}$ orientation provides a larger active surface area for the conductive polymer, which enables greater availability, resulting in better efficiency for the further functionalization with $\mathrm{CNOs}_{\mathrm{ox}}$. There is also a higher probability of filling the empty core of the nanotubes by carbon nanoparticles, which have a diameter that is approximately 20 times smaller. An active and highly developed surface area is the most important parameter for materials that are used as electrodes in supercapacitor devices, which defines their electrochemical properties. The capacitance of such systems is directly proportional to the surface of the electrodes that is available for transport of the electrolyte ions.

Figure 6 shows SEM images for PANI $\mathrm{PTS}_{\text {s }}$ modified with $\mathrm{CNOs}_{\mathrm{ox}}$ at varying concentrations. The functionalization of the polymer nanotubes with $\mathrm{CNOs}_{\mathrm{ox}}$ was carried out in the presence of water-soluble EDC and NHS, as described previously (Scheme 3). Despite the very small size of the carbon nanoparticles $(\sim 5 \mathrm{~nm})$, the SEM images do not exhibit single and separated $\mathrm{CNOs}_{\mathrm{ox}}$ particles. The van der Waals forces between the oxidized carbon nanoparticles lead to self-aggregation and the formation of nanoclusters, and their amount and distribution are concentration-dependent (Figure 6B-D). The aggregates of carbon nanoparticles with different dimensions formed a spongy-like structure. The $\mathrm{CNO}_{\mathrm{ox}}$ particles were accumulated both between and onto $\mathrm{PANI}_{\mathrm{NT}}$. The SEM images 
show the difference between pristine $\mathrm{PANI}_{\mathrm{NT}}$ (Figure $6 \mathrm{~A}$ ) and $\mathrm{PANI}_{\mathrm{NT}} / \mathrm{CNO}_{\mathrm{ox}}$ nanocomposites, even for low concentrations of $\mathrm{CNOs}_{\mathrm{ox}}$ (Figure 6B).

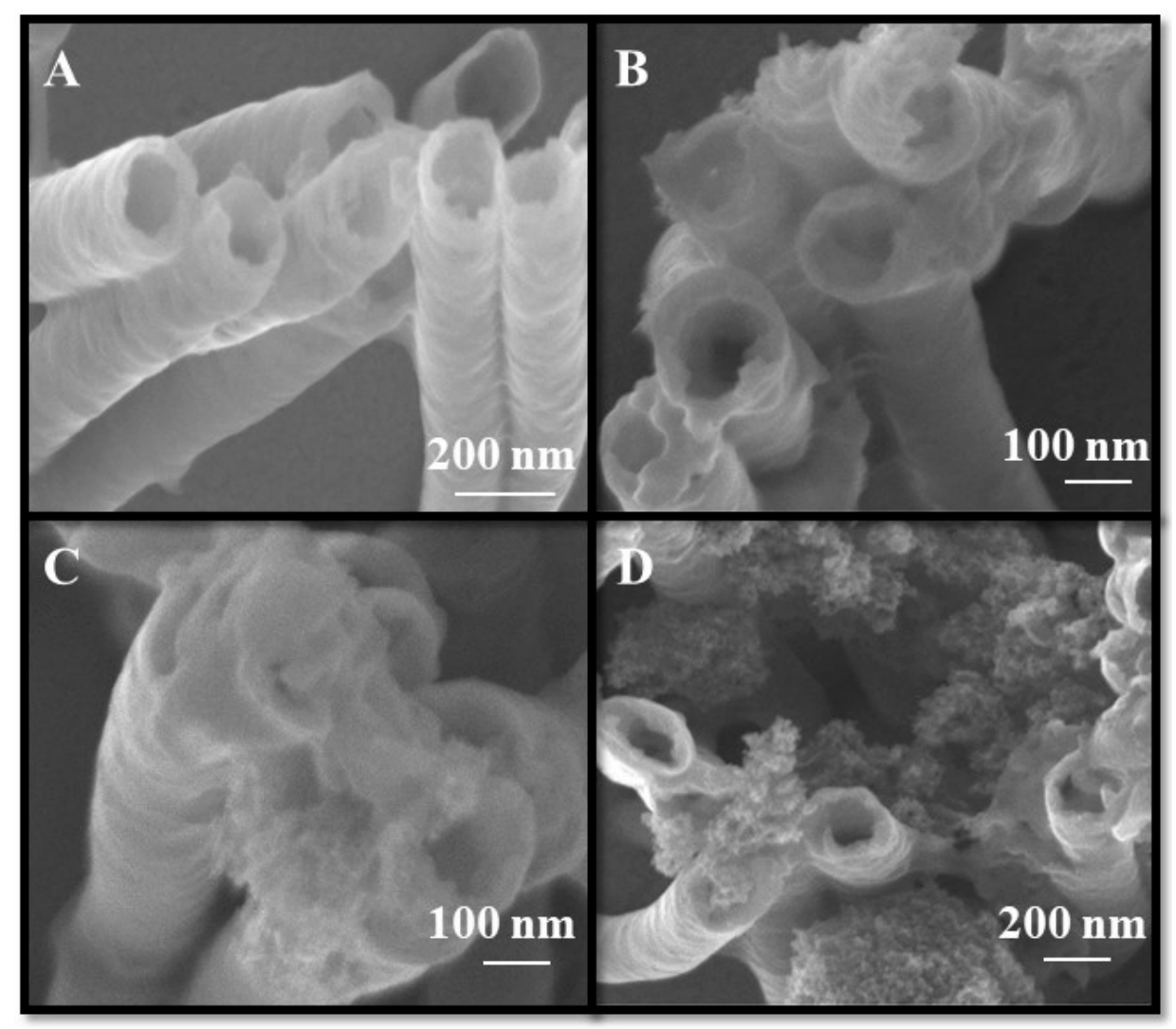

Figure 6. SEM images of (A) vertically oriented $\mathrm{PANI}_{\mathrm{NT}}$ on an $\mathrm{Au}$ surface, pristine $\mathrm{PANI}_{\mathrm{NT}}$, and $\mathrm{PANI}_{\mathrm{NT}}$ functionalized with $\mathrm{CNOs}_{\mathrm{ox}}$ : (B) $0.5 \mathrm{mg} \mathrm{mL}^{-1}$, (C) $1 \mathrm{mg} \mathrm{mL}^{-1}$, and (D) $4 \mathrm{mg} \mathrm{mL}^{-1}$.

\subsection{Voltammetric Studies of the PANI $\mathrm{NT}_{\mathrm{C}} / \mathrm{CNO}_{\text {ox }}$ Nanocomposite}

The $\mathrm{PANI}_{\mathrm{NT}} / \mathrm{CNO}_{\text {ox }}$ nanocomposites and undoped $\mathrm{PANI} \mathrm{NT}_{\text {as }} \mathrm{GC} / \mathrm{Au}-\mathrm{PANI} \mathrm{NT}_{\mathrm{NT}} / \mathrm{CNO}_{\mathrm{ox}}$ and $\mathrm{GC} / \mathrm{Au}-\mathrm{PANI} \mathrm{NT}_{\mathrm{NT}}$ were examined using cyclic voltammetry $(\mathrm{CV})$. Nanocomposites anchored to a thin gold film were immobilized onto the GC electrode surface (Scheme 2). Such a system enables the evaluation of the electrochemical performance and charge storage ability of these systems. The measurements were conducted in one $\mathrm{M}$ of sulfuric acid solution within the $0-0.8 \mathrm{~V}$ potential range versus $\mathrm{Ag} / \mathrm{AgCl}$. The voltammetric curves were recorded using different sweep rates of up to $100 \mathrm{mV} \mathrm{s}^{-1}$. The voltammetric responses for pure $\mathrm{PANI}_{\mathrm{NT}}$ and $\mathrm{PANI}_{\mathrm{NT}} / \mathrm{CNO}_{\mathrm{ox}}$ (four $\mathrm{mg} \mathrm{mL}^{-1}$ of CNOs) composites are shown in Figure 7. The PANI $\mathrm{NT}_{\mathrm{N}}$ film exhibited good mechanical and electrochemical stability under cyclic voltammetric conditions within the applied potential range (Figure 7A). Figure 7A,B present the $10^{\text {th }}$ cycle of the $\mathrm{CV}$ measurements, and the shape of the $\mathrm{CV}$ curves remain essentially unchanged. The characteristic $C V$ response for pristine $\mathrm{PANI}_{\mathrm{NT}}$ in acidic medium consists of two pairs of redox couples $\left(A_{1} / C_{1}\right.$ and $\left.A_{2} / C_{2}\right)$ corresponding to two-electron processes. The peaks $A_{1} / C_{1}$ within the $0-0.25 \mathrm{~V}$ potential range are attributed to the electrochemical transition between semiconducting leucoemeraldine and the conductive emeraldine form. The peaks $\mathrm{A}_{2} / \mathrm{C}_{2}$ occurring in a more positive potential range are attributed to the benzoquinone to aminoquinone transformation [64]. 

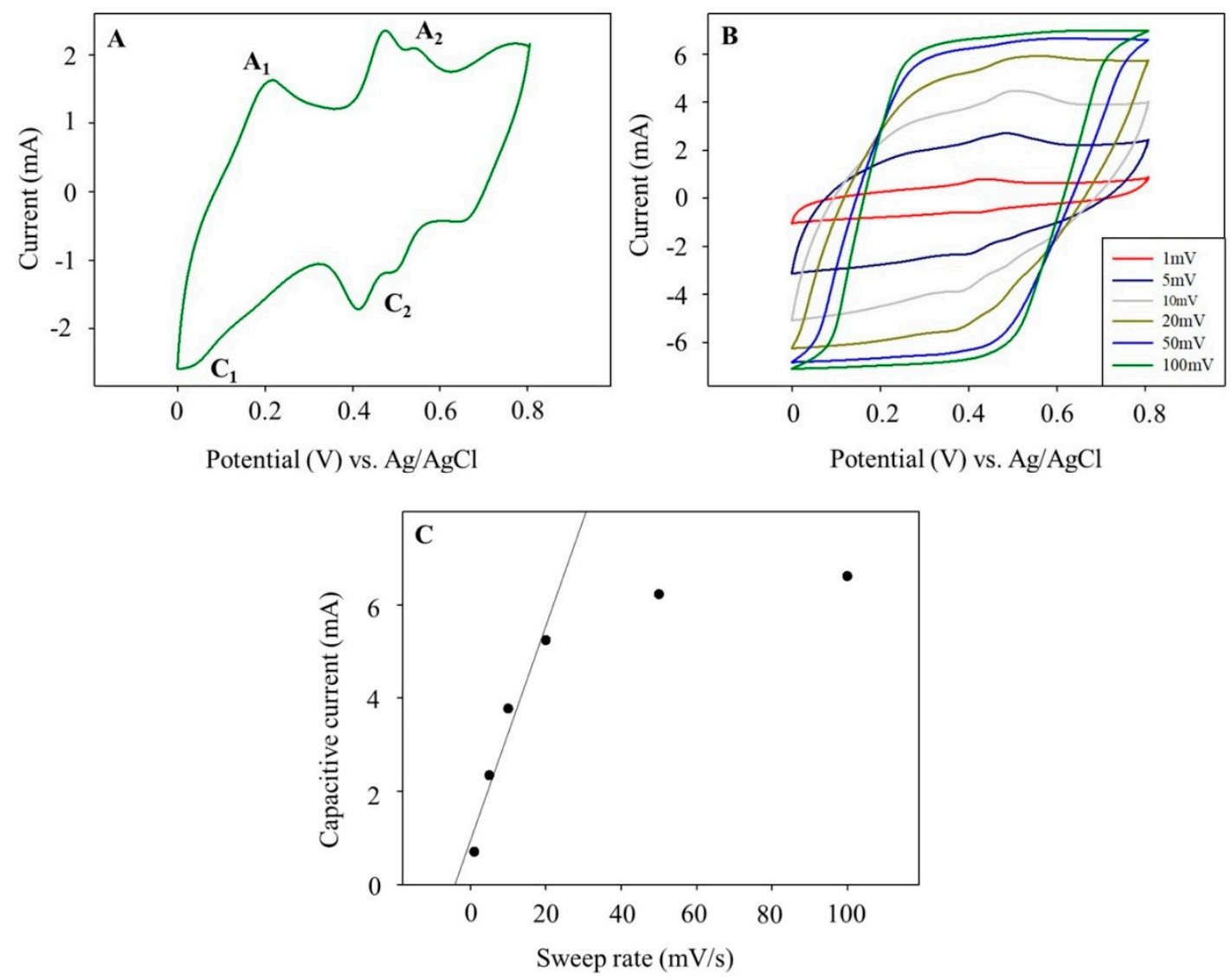

Figure 7. Cyclic voltammograms for (A) pristine $\mathrm{Au}-\mathrm{PANI}_{\mathrm{NT}}$ at one $\mathrm{mV} \mathrm{s}^{-1}$ and (B) $\mathrm{Au}-\mathrm{PANI}_{\mathrm{NT}} / \mathrm{CNOs}_{\mathrm{ox}}\left(4 \mathrm{mg} \mathrm{mL}{ }^{-1}\right.$ of $\mathrm{CNOs}_{\mathrm{ox}}$ ) nanocomposite immobilized on a GC electrode for varying sweep rates: $1 \mathrm{mV} \mathrm{s}^{-1}, 5 \mathrm{mV} \mathrm{s}^{-1}, 10 \mathrm{mV} \mathrm{s}^{-1}, 20 \mathrm{mV} \mathrm{s}^{-1}, 50 \mathrm{mV} \mathrm{s}^{-1}$, and $100 \mathrm{mV} \mathrm{s}^{-1}$ in $1 \mathrm{M}$ $\mathrm{H}_{2} \mathrm{SO}_{4}$. (C) The capacitive current $\left(I_{C}\right)$ vs. sweep rate dependence.

The $\mathrm{PANI}_{\mathrm{NT}} / \mathrm{CNOs}_{\mathrm{ox}}$ film exhibited stable and conductive behavior under cyclic voltammetric conditions within this potential range (Figure 7B). The capacitance current depends on the sweep rates and the film composition. The conductivity of this composite arises mainly from the $\mathrm{CNOs}_{\mathrm{ox}}$ component. The electrochemical responses also indicate the presence of a pair of redox peaks, confirming the contribution of the PANI nanostructures to the capacitance of the composites. The less clarity of PANI $\mathrm{PT}_{\mathrm{NT}}$ redox peaks even at low scan rates is caused by the $\mathrm{CNOs}_{\mathrm{ox}}$ presence, which restricts the electrolyte access to the polymer nanotubes. The $\mathrm{PANI}_{\mathrm{NT}}$ signals decreased with the increasing sweep rate. The voltammograms for the $\mathrm{PANI}_{\mathrm{NT}} / \mathrm{CNOs}_{\mathrm{ox}}$ measured at sweep rates higher than $50 \mathrm{mV}$ $\mathrm{s}^{-1}$ show almost pseudo-rectangular anodic and cathodic profiles, which reflects a practically ideal double-layer capacitance behavior. The capacitive current varies linearly with the sweep rate below $50 \mathrm{mV} \mathrm{s}^{-1}$ at $+0.3 \mathrm{~V}$ versus $\mathrm{Ag} / \mathrm{AgCl}$, as shown in Figure $7 \mathrm{C}$. The deviations from linear dependence of the capacitive current above $50 \mathrm{mV} \mathrm{s}^{-1}$ are the results of the electrolyte diffusion limitation. The capacitive current $\left(I_{c}\right)$ is given by Equation 1 :

$$
I_{c}=C_{s} v m
$$

in which $C_{S}$ is the specific capacitance, $m$ is the mass deposited onto the electrode surface, and $v$ is the potential sweep rate. It should be noticed that the mass parameter is directly connected to the active surface of the material, according to Equation (2):

$$
m=A \rho_{A}
$$


where $\rho_{A}$ is the average area density, and $A$ is the active surface area of material. The values for $C_{S}$ calculated from the dependence of the current on the different sweep rates for undoped PANI and the composites are collected in Table 1 . The $C_{s}$ for the undoped PANI and $\mathrm{PANI}_{\mathrm{NT}} / \mathrm{CNOs}_{\mathrm{ox}}$ composite using CV was also determined from the following Equation (3):

$$
C_{S}=\frac{\int_{\mathrm{E}_{2}}^{\mathrm{E}_{1}} i(E) d E}{v m\left(E_{1}-E_{2}\right)}
$$

where $E_{1}$ and $E_{2}$ are the initial and final potentials $(\mathrm{V})$, respectively, $\int_{\mathrm{E}_{2}}^{\mathrm{E}_{1}} i(E) d E$ is the integrated current over the potential window, $v$ is the sweep rate $\left(\mathrm{V} \mathrm{s}^{-1}\right)$, and $m$ is the mass of the active material. The values of the specific capacitances obtained by the integration of $I$ versus $E$ curves are slightly different compared to those calculated from the linear relationship for the $I$ versus $v$ plots (Table 1 ). A larger difference of the calculated $C_{s}$ values is observed for low sweep rates $\left(<5 \mathrm{mV} \mathrm{s}^{-1}\right)$. For both cases, the specific capacitances for the nanocomposite are higher than those obtained for the pristine $\mathrm{PANI}_{\mathrm{NT}}$.

Table 1. Specific capacitance of pristine $\mathrm{PANI}_{\mathrm{NT}}$ and $\mathrm{PANI}_{\mathrm{NT}} / \mathrm{CNO}_{\mathrm{ox}}$ composites calculated based on the voltammetric studies.

\begin{tabular}{|c|c|c|c|c|}
\hline \multirow[b]{3}{*}{ Sweep rate $\left(\mathrm{mV} \mathrm{s}^{-1}\right)$} & \multicolumn{4}{|c|}{ Specific Capacitance $\left(\mathrm{F}^{-1}\right)$} \\
\hline & \multicolumn{2}{|c|}{ Pristine $\mathrm{PANI}_{\mathrm{NT}}$} & \multicolumn{2}{|c|}{ PANI $_{\mathrm{NT}} / \mathrm{CNOs}_{\mathrm{ox}}$ Composite } \\
\hline & $C_{1}$ & $C_{2}$ & $C_{1}$ & $C_{2}$ \\
\hline 1 & 237 & 269 & 795 & 946 \\
\hline 5 & - & - & 741 & 681 \\
\hline 10 & - & - & 616 & 614 \\
\hline 20 & - & - & 431 & 441 \\
\hline 50 & - & - & 213 & 200 \\
\hline 100 & 53 & 70 & 115 & 169 \\
\hline
\end{tabular}

The capacitance value calculated using Equation (2) at $1 \mathrm{mV} \mathrm{s}^{-1}$ is $946 \mathrm{~F} \mathrm{~g}^{-1}$, which is much higher than that for pristine PANI $\mathrm{NT}_{\mathrm{NT}}\left(269 \mathrm{~F} \mathrm{~g}^{-1}\right)$ (Table 1). It is possible that this is due to the $\mathrm{PANI}_{\mathrm{NT}} / \mathrm{CNO}_{\mathrm{ox}}$ surface area increase while maintaining the electroactive behavior. The dependence of the specific capacitance versus scan rate shows that the $\mathrm{PANI}_{\mathrm{NT}} / \mathrm{CNOs}_{\mathrm{ox}}$ nanocomposites are capable of storing more electric charge compared to pristine $\mathrm{PANI}_{\mathrm{NT}}$, regardless of the sweep rate. It is also important to note that the specific capacitance for PANI $\mathrm{NT}_{\mathrm{N}}$ reveals a more linear behavior compared to that for the nanocomposites within the same sweep rate range. When the sweep rate was increased to $10 \mathrm{mV} \mathrm{s}^{-1}$, the capacitive current for the nanocomposite decreased and represented only ca. $65 \%$ of the starting value. However, the shape of the $\mathrm{CV}$ curves remain essentially unchanged even at high scan rates, suggesting that the electrode exhibits excellent charge transport, while the gravimetric capacitance gradually decreased upon increasing the scan rate.

The data show that the $\mathrm{PANI}_{\mathrm{NT}} / \mathrm{CNO}_{\mathrm{ox}}$ nanocomposites are ideal materials for supercapacitors. Compared to other systems described in the literature that contain carbon nanoparticles and PANI (Table 2), our nanocomposites exhibit better electrochemical properties, including a notably higher specific capacitance. The higher values of specific capacitance for the $\mathrm{PANI}_{\mathrm{NT}} / \mathrm{CNOs}_{\mathrm{ox}}$ nanocomposite result from the high conductivity of both nanostructures, due to their extremely high porosity and organized brush-like structures. In particular, "conductive" channels were created in which the interactions between $\pi$-electrons of the PANI aromatic/quinonoid structures and CNO graphitic layers facilitate charge transport. The high effectiveness of supercapacitor devices containing $\mathrm{PANI}_{\mathrm{NT}} / \mathrm{CNOs}_{\mathrm{Ox}}$ can also be realized due to the specific nanocomposite architecture, in which the 
nanotubes are oriented vertically to the surface, thus providing easy access for the electrolyte and facilitating ion diffusion.

Table 2. Electrochemical performance of various composites for supercapacitors based on PANI electroactive material.

\begin{tabular}{|c|c|c|c|c|c|}
\hline Material & $\begin{array}{l}\text { Sweep Rate } \\
\left(\mathrm{mV} \mathrm{s}^{-1}\right)\end{array}$ & $\begin{array}{l}\text { Potential } \\
\text { Range (V) }\end{array}$ & Electrolyte & $\begin{array}{l}\text { Specific Capacitance } \\
\left(\mathrm{F} \mathrm{g}^{-1}\right)\end{array}$ & References \\
\hline PANI & 10 & $-0.1-0.8$ & $1 \mathrm{M} \mathrm{H}_{2} \mathrm{SO}_{4}$ & 503 & [15]. \\
\hline PANI & 10 & $-0.2-0.6$ & Nafion & 269 & {$[64]$} \\
\hline Nanofibrous PANI & 10 & $-0.1-0.8$ & $1 \mathrm{M} \mathrm{H}_{2} \mathrm{SO}_{4}$ & 839 & [65] \\
\hline Nanofibrous PANI & 10 & $-0.1-0.8$ & $1 \mathrm{M} \mathrm{H}_{2} \mathrm{SO}_{4}$ & 861 & [66] \\
\hline $\begin{array}{l}\text { Hydrogel-assisted } \\
\text { PANI microfiber }\end{array}$ & 10 & $-0.2-0.8$ & $\begin{array}{l}1 \mathrm{M} \text { methane } \\
\text { sulfonic acid }\end{array}$ & 703 & [67] \\
\hline $\mathrm{BF}_{4}$-doped PANI & 50 & $0-0.75$ & $4 \mathrm{M} \mathrm{HBF}$ & 74 & [68] \\
\hline PANI/CNT & 5 & $-0.1-0.7$ & $\mathrm{PVA} / \mathrm{H}_{3} \mathrm{PO}_{4}$ & 440 & [69] \\
\hline PANI/MWCNT & 1 & $0-1.0$ & $0.1 \mathrm{M} \mathrm{H}_{2} \mathrm{SO}_{4}$ & 560 & [33] \\
\hline $\begin{array}{l}\text { Mesoporous } \\
\text { C/PANI }\end{array}$ & 2 & $-0.1-1.0$ & $1 \mathrm{M} \mathrm{H}_{2} \mathrm{SO}_{4}$ & 470 & [70] \\
\hline PANI on CNF & 5 & $0-0.8$ & $1 \mathrm{M} \mathrm{H}_{2} \mathrm{SO}_{4}$ & 264 & [71] \\
\hline PANI/GO & 1 & $-0.1-0.9$ & $1 \mathrm{M} \mathrm{H}_{2} \mathrm{SO}_{4}$ & 1136 & [72] \\
\hline $\mathrm{G} / \mathrm{Fe}_{2} \mathrm{O}_{3} / \mathrm{PANI}$ & 1 & $-1.0-0.1$ & $1 \mathrm{M} \mathrm{KOH}$ & 638 & [73] \\
\hline $\mathrm{PANI}_{\mathrm{NT}} / \mathrm{CNOs}_{\mathrm{ox}}$ & 1 & $0-0.8$ & $1 \mathrm{M} \mathrm{H}_{2} \mathrm{SO}_{4}$ & 946 & this work \\
\hline $\mathrm{PANI}_{\mathrm{NT}} / \mathrm{CNOs}_{\mathrm{ox}}$ & 10 & $0-0.8$ & $1 \mathrm{M} \mathrm{H}_{2} \mathrm{SO}_{4}$ & 614 & this work \\
\hline
\end{tabular}

Values for the specific capacitance of undoped PANI and composites containing this polymer and other CNs measured at low sweep rates are collected in Table 2. As observed from the CVs, the composites exhibited better electrochemical performance compared to most of the undoped conducting polymers. Additionally, it should be noted that the electrochemical properties of the composites are affected by the type of carbon nanostructures and the form of the conducting polymer.

\section{Conclusions}

We demonstrated that nanocomposites containing PANI nanotubes and carbon nano-onions can be prepared by the template method. The combination of these two types of materials improved the capacitive properties. Notably, the nanostructural properties of both components and the unique perpendicular organization of the conducting nanotubes relative to the surface electrode affected the unusual electrochemical properties of these materials. The electrochemical performance of the composites is affected by the mass of the carbon nanostructures. The $\mathrm{PANI}_{\mathrm{NT}} / \mathrm{CNO}_{\mathrm{ox}}$ composites exhibited a high specific capacitance ca. $950 \mathrm{~F} \mathrm{~g}^{-1}$, which is one of the highest values published to date for analogous materials. The main advantage of these composites is their potential for use as conductive materials in solid-state supercapacitors.

Author Contributions: Methodology, M.G.; Supervision, M.E.P.-B.; Writing original draft, P.O.; Writing review \& editing, L.E. and M.E.P.-B.

Acknowledgments: The authors thank the National Science Center (NSC), Poland, for the generous support of this work (grants: \#2016/20/S/ST5/00371 to P.O. and \#2012/05/E/ST5/03800 to M.E.P.-B.). L.E. thanks the Robert A. Welch Foundation for an endowed chair, grant \#AH-0033 and the United State National Science Foundation, grants: Partnerships for Research and Education in Materials program (DMR-1205302) and CHE-1408865.

Conflicts of Interest: The authors declare no competing financial interest. 


\section{References}

1. Mosa, I.M.; Pattammattel, A.; Kadimisetty, K.; Pande, P.; El-Kady, M.F.; Bishop, G.W.; Novak, M.; Kaner, R.B.; Basu, A.K.; Kumar, C.V.; et al. Ultrathin Graphene-Protein Supercapacitors for Miniaturized Bioelectronics. Adv. Energy Mater. 2017, 7, 1700358. [CrossRef] [PubMed]

2. Snook, G.A.; Kao, P.; Best, A.S. Conducting-polymer-based supercapacitor devices and electrodes. J. Power Sources 2011, 196,1-12. [CrossRef]

3. Ke, Q.; Wang, J. Graphene-based materials for supercapacitor electrodes-A review. J. Materiomics 2016, 2, 37-54. [CrossRef]

4. Hong, S.-Y.; Park, S.-M. Electrochemistry of Conductive Polymers 36. pH Dependence of Polyaniline Conductivities Studied by Current-Sensing Atomic Force Microscopy. J. Phys. Chem. B 2005, 109, 9305-9310. [CrossRef]

5. Prigodin, V.N.; Hsu, F.C.; Park, J.H.; Waldmann, O.; Epstein, A.J. Electron-ion interaction in doped conducting polymers. Phys. Rev. B 2008, 78, 035203. [CrossRef]

6. Focke, W.W.; Wnek, G.E.; Wei, Y. Influence of oxidation state, $\mathrm{pH}$, and counterion on the conductivity of polyaniline. J. Phys. Chem. 1987, 91, 5813-5818. [CrossRef]

7. Parthasarathy, R.V.; Martin, C.R. Template-Synthesized Polyaniline Microtubules. Chem. Mater. 1994, 6, 1627-1632. [CrossRef]

8. Chen, T.; Dai, L. Carbon nanomaterials for high-performance supercapacitors. Mater. Today 2013, 16, $272-280$. [CrossRef]

9. Grover, S.; Goel, S.; Marichi, R.B.; Sahu, V.; Singh, G.; Sharma, R.K. Polyaniline All Solid-State Pseudocapacitor: Role of Morphological Variations in Performance Evolution. Electrochim. Acta 2016, 196, 131-139. [CrossRef]

10. Yoon, H.; Jang, J. Conducting-Polymer Nanomaterials for High-Performance Sensor Applications: Issues and Challenges. Adv. Funct. Mater. 2009, 19, 1567-1576. [CrossRef]

11. Sutar, D.S.; Major, S.S.; Srinivasa, R.S.; Yakhmi, J.V. Conformational morphology of polyaniline grown on self-assembled monolayer modified silicon. Thin Solid Films 2011, 520, 351-355. [CrossRef]

12. Chaudhari, S.; Patil, P.P. Inhibition of nickel coated mild steel corrosion by electrosynthesized polyaniline coatings. Electrochim. Acta 2011, 56, 3049-3059. [CrossRef]

13. Wang, H.; Wang, L.; Wang, R.; Tian, X. Novel route to polyaniline nanofibers from miniemulsion polymerization. J. Mater. Sci. 2011, 46, 1049-1052. [CrossRef]

14. Cui, Z.; Coletta, C.; Rebois, R.; Baiz, S.; Gervais, M.; Goubard, F.; Aubert, P.H.; Dazzi, A.; Remita, S. Radiation-induced reduction-polymerization route for the synthesis of PEDOT conducting polymers. Radiat. Phys. Chem. 2016, 119, 157-166. [CrossRef]

15. Dhawale, D.S.; Vinu, A.; Lokhande, C.D. Stable nanostructured polyaniline electrode for supercapacitor application. Electrochim. Acta 2011, 56, 9482-9487. [CrossRef]

16. Martin, C.R. Template Synthesis of Electronically Conductive Polymer Nanostructures. Acc. Chem. Res. 1995, 28, 61-68. [CrossRef]

17. Mazur, M.; Tagowska, M.; Pałys, B.; Jackowska, K. Template synthesis of polyaniline and poly(2-methoxyaniline) nanotubes: Comparison of the formation mechanisms. Electrochem. Commun. 2003, 5, 403-407. [CrossRef]

18. Olejnik, P.; Gniadek, M.; Palys, B. Layers of polyaniline nanotubes deposited by langmuir-blodgett method. J. Phys. Chem. C 2012, 116, 10424-10429. [CrossRef]

19. Long, Y.Z.; Li, M.M.; Gu, C.; Wan, M.; Duvail, J.L.; Liu, Z.; Fan, Z. Recent advances in synthesis, physical properties and applications of conducting polymer nanotubes and nanofibers. Prog. Polym. Sci. 2011, 36, 1415-1442. [CrossRef]

20. Zhang, Z.; Deng, J.; Wan, M. Highly crystalline and thin polyaniline nanofibers oxidized by ferric chloride. Mater. Chem. Phys. 2009, 115, 275-279. [CrossRef]

21. Rahy, A.; Yang, D.J. Synthesis of highly conductive polyaniline nanofibers. Mater. Lett. 2008, 62, $4311-4314$. [CrossRef]

22. Delvaux, M.; Duchet, J.; Stavaux, P.-Y.; Legras, R.; Demoustier-Champagne, S. Chemical and electrochemical synthesis of polyaniline micro- and nano-tubules. Synth. Met. 2000, 113, 275-280. [CrossRef] 
23. Boulanger, N.; Barbero, D.R. Ordered and Highly Conductive Carbon Nanotube Nano-Networks in a Semiconducting Polymer Film by Solution Processing. Adv. Electron. Mater. 2015, 1, 1400030. [CrossRef]

24. Li, L.; Qiu, J.; Wang, S. Three-dimensional ordered nanostructures for supercapacitor electrode. Electrochim. Acta 2013, 99, 278-284. [CrossRef]

25. Kiamahalleh, M.V.; Sata, S.A.; Buniran, S.; Sharif Zein, S.H. Remarkable Stability of Supercapacitor Material Synthesized by Manganese Oxide Filled in Multiwalled Carbon Nanotubes. Curr. Nanosci. 2010, 6, 553-559. [CrossRef]

26. Mondal, C.; Ghosh, D.; Aditya, T.; Sasmal, A.K.; Pal, T. $\mathrm{Mn}_{3} \mathrm{O}_{4}$ nanoparticles anchored to multiwall carbon nanotubes: A distinctive synergism for high-performance supercapacitors. New J. Chem. 2015, 39, 8373-8380. [CrossRef]

27. Wang, H.; Lin, J.; Shen, Z.X. Polyaniline (PANi) based electrode materials for energy storage and conversion. J. Sci. Adv. Mater. Devices 2016, 1, 225-255. [CrossRef]

28. Papathanassiou, A.N.; Mykhailiv, O.; Echegoyen, L.; Sakellis, I.; Plonska-Brzezinska, M.E. Electric properties of carbon nano-onion/polyaniline composites: A combined electric modulus and ac conductivity study. J. Phys. Appl. Phys. 2016, 49, 285305. [CrossRef]

29. Mykhailiv, O.; Imierska, M.; Petelczyc, M.; Echegoyen, L.; Plonska-Brzezinska, M.E. Chemical versus Electrochemical Synthesis of Carbon Nano-onion/Polypyrrole Composites for Supercapacitor Electrodes. Chem. Eur. J. 2015, 21, 5783-5793. [CrossRef] [PubMed]

30. Papathanassiou, A.N.; Plonska-Brzezinska, M.E.; Mykhailiv, O.; Echegoyen, L.; Sakellis, I. Combined high permittivity and high electrical conductivity of carbon nano-onion/polyaniline composites. Synth. Met. 2015, 209, 583-587. [CrossRef]

31. Grądzka, E.; Winkler, K.; Borowska, M.; Plonska-Brzezinska, M.E.; Echegoyen, L. Comparison of the electrochemical properties of thin films of MWCNTs/C60-Pd, SWCNTs/C60-Pd and ox-CNOs/C60-Pd. Electrochim. Acta 2013, 96, 274-284. [CrossRef]

32. Gupta, V.; Miura, N. Polyaniline/single-wall carbon nanotube (PANI/SWCNT) composites for high performance supercapacitors. Electrochim. Acta 2006, 52, 1721-1726. [CrossRef]

33. Zhou, Y.; Qin, Z.Y.; Li, L.; Zhang, Y.; Wei, Y.L.; Wang, L.F.; Zhu, M.F. Polyaniline/multi-walled carbon nanotube composites with core-shell structures as supercapacitor electrode materials. Electrochim. Acta 2010, 55, 3904-3908. [CrossRef]

34. Ning, G.; Li, T.; Yan, J.; Xu, C.; Wei, T.; Fan, Z. Three-dimensional hybrid materials of fish scale-like polyaniline nanosheet arrays on graphene oxide and carbon nanotube for high-performance ultracapacitors. Carbon 2013, 54, 241-248. [CrossRef]

35. Lee, T.; Yun, T.; Park, B.; Sharma, B.; Song, H.-K.; Kim, B.-S. Hybrid multilayer thin film supercapacitor of graphene nanosheets with polyaniline: Importance of establishing intimate electronic contact through nanoscale blending. J. Mater. Chem. 2012, 22, 21092-21099. [CrossRef]

36. Al-Jishi, R.; Dresselhaus, G. Lattice-dynamical model for graphite. Phys. Rev. B 1982, $26,4514-4522$. [CrossRef]

37. Bacon, R. Growth, Structure, and Properties of Graphite Whiskers. J. Appl. Phys. 1960, 31, 283-290. [CrossRef]

38. Banhart, F. Structural transformations in carbon nanoparticles induced by electron irradiation. Phys. Solid State 2002, 44, 399-404. [CrossRef]

39. Bystrzejewski, M.; Rummeli, M.H.; Gemming, T.; Lange, H.; Huczko, A. Catalyst-free synthesis of onion-like carbon nanoparticles. New Carbon Mater. 2010, 25, 1-8. [CrossRef]

40. Cabioc'h, T.; Jaouen, M.; Rivière, J.P.; Delafond, J.; Hug, G. Characterization and growth of carbon phases synthesized by high temperature carbon ion implantation into copper. Diam. Relat. Mater. 1997, 6, 261-265. [CrossRef]

41. Palkar, A.; Melin, F.; Cardona, C.M.; Elliott, B.; Naskar, A.K.; Edie, D.D.; Kumbhar, A.; Echegoyen, L. Reactivity Differences between Carbon Nano Onions (CNOs) Prepared by Different Methods. Chem. Asian J. 2007, 2, 625-633. [CrossRef] [PubMed]

42. Gruen, D.M.; Shenderova, O.A.; Vul', A.Y. (Eds.) Synthesis, Properties and Applications of Ultrananocrystalline Diamond; Springer: Berlin/Heidelberg, Germany, 2005; Volume 192.

43. Plonska-Brzezinska, M.E.; Echegoyen, L. Carbon nano-onions for supercapacitor electrodes: Recent developments and applications. J. Mater. Chem. A 2013, 1, 13703-13714. [CrossRef] 
44. Mykhailiv, O.; Zubyk, H.; Plonska-Brzezinska, M.E. Carbon nano-onions: Unique carbon nanostructures with fascinating properties and their potential applications. Inorg. Chim. Acta 2017, 468, 49-66. [CrossRef]

45. Bartelmess, J.; Giordani, S. Carbon nano-onions (multi-layer fullerenes): Chemistry and applications. Beilstein J. Nanotechnol. 2014, 5, 1980-1998. [CrossRef] [PubMed]

46. Bobrowska, D.M.; Brzezinski, K.; Echegoyen, L.; Plonska-Brzezinska, M.E. A new perspective on carbon nano-onion/nickel hydroxide/oxide composites: Physicochemical properties and application in hybrid electrochemical systems. Fuller. Nanotub. Carbon Nanostruct. 2017, 25, 193-203. [CrossRef]

47. Bobrowska, D.M.; Czyrko, J.; Brzezinski, K.; Echegoyen, L.; Plonska-Brzezinska, M.E. Carbon nano-onion composites: Physicochemical characteristics and biological activity. Fuller. Nanotub. Carbon Nanostruct. 2017, 25, 185-192. [CrossRef]

48. Kuznetsov, V.L.; Chuvilin, A.L.; Moroz, E.M.; Kolomiichuk, V.N.; Shaikhutdinov, S.K.; Butenko, Y.V.; Mal'kov, I.Y. Effect of explosion conditions on the structure of detonation soots: Ultradisperse diamond and onion carbon. Carbon 1994, 32, 873-882. [CrossRef]

49. Wong, S.S.; Woolley, A.T.; Joselevich, E.; Cheung, C.L.; Lieber, C.M. Covalently-Functionalized Single-Walled Carbon Nanotube Probe Tips for Chemical Force Microscopy. J. Am. Chem. Soc. 1998, 120, 8557-8558. [CrossRef]

50. Salzmann, C.G.; Llewellyn, S.A.; Tobias, G.; Ward, M.A.H.; Huh, Y.; Green, M.L.H. The Role of Carboxylated Carbonaceous Fragments in the Functionalization and Spectroscopy of a Single-Walled Carbon-Nanotube Material. Adv. Mater. 2007, 19, 883-887. [CrossRef]

51. Pujals, D.C.; de Fuentes, O.A.; García, L.F.D.; Cazzanelli, E.; Caputi, L.S. Raman spectroscopy of polyhedral carbon nano-onions. Appl. Phys. A 2015, 120, 1339-1345. [CrossRef]

52. Bogdanov, K.; Fedorov, A.; Osipov, V.; Enoki, T.; Takai, K.; Hayashi, T.; Ermakov, V.; Moshkalev, S.; Baranov, A. Annealing-induced structural changes of carbon onions: High-resolution transmission electron microscopy and Raman studies. Carbon 2014, 73, 78-86. [CrossRef]

53. Liu, P.; Zhu, Y.; Torres, J.; Lee, S.H.; Yun, M. Facile and template-free method toward chemical synthesis of polyaniline film/nanotube structures. J. Polym. Sci. Part Polym. Chem. 2017, 55, 3973-3979. [CrossRef]

54. Do Nascimento, G.M.; Temperini, M.R.L. Studies on the resonance Raman spectra of polyaniline obtained with near-IR excitation. J. Raman Spectrosc. 2008, 39, 772-778. [CrossRef]

55. Tucceri, R.; Arnal, P.M.; Scian, A.N. Spectroscopic Characterization of Poly(ortho-Aminophenol) Film Electrodes: A Review Article. J. Spectrosc. 2013, 2013, 951604. [CrossRef]

56. Ćirić-Marjanović, G.; Trchová, M.; Stejskal, J. The chemical oxidative polymerization of aniline in water: Raman spectroscopy. J. Raman Spectrosc. 2008, 39, 1375-1387. [CrossRef]

57. Šeděnková, I.; Trchová, M.; Stejskal, J. Thermal degradation of polyaniline films prepared in solutions of strong and weak acids and in water-FTIR and Raman spectroscopic studies. Polym. Degrad. Stab. 2008, 93, 2147-2157. [CrossRef]

58. Jabłońska, A.; Gniadek, M.; Pałys, B. Enhancement of Direct Electrocatalytic Activity of Horseradish Peroxidase on Polyaniline Nanotubes. J. Phys. Chem. C 2015, 119, 12514-12522. [CrossRef]

59. Trchová, M.; Stejskal, J. Polyaniline: The infrared spectroscopy of conducting polymer nanotubes (IUPAC Technical Report). Pure Appl. Chem. 2011, 83, 1803-1817. [CrossRef]

60. Trchová, M.; Morávková, Z.; Bláha, M.; Stejskal, J. Raman spectroscopy of polyaniline and oligoaniline thin films. Electrochim. Acta 2014, 122, 28-38. [CrossRef]

61. Morsi, R.E.; Khamis, E.A.; Al-Sabagh, A.M. Polyaniline nanotubes: Facile synthesis, electrochemical, quantum chemical characteristics and corrosion inhibition efficiency. J. Taiwan Inst. Chem. Eng. 2016, 60, 573-581. [CrossRef]

62. Plonska-Brzezinska, M.E.; Dubis, A.T.; Lapinski, A.; Villalta-Cerdas, A.; Echegoyen, L. Electrochemical Properties of Oxidized Carbon Nano-Onions: DRIFTS-FTIR and Raman Spectroscopic Analyses. ChemPhysChem 2011, 12, 2659-2668. [CrossRef]

63. Wang, S.; Ma, L.; Gan, M.; Fu, S.; Dai, W.; Zhou, T.; Sun, X.; Wang, H.; Wang, H. Free-standing 3D graphene/polyaniline composite film electrodes for high-performance supercapacitors. J. Power Sources 2015, 299, 347-355. [CrossRef]

64. Kim, B.; Kwon, J.; Ko, J.; Park, J.; Too, C.; Wallace, G. Preparation and enhanced stability of flexible supercapacitor prepared from nafion/polyaniline nano-fiber. Synth. Met. 2010, 160, 94-98. [CrossRef] 
65. Dhawale, D.S.; Dubal, D.P.; Jamadade, V.S.; Salunkhe, R.R.; Lokhande, C.D. Fuzzy nanofibrous network of polyaniline electrode for supercapacitor application. Synth. Met. 2010, 160, 519-522. [CrossRef]

66. Dhawale, D.S.; Salunkhe, R.R.; Jamadade, V.S.; Dubal, D.P.; Pawar, S.M.; Lokhande, C.D. Hydrophilic polyaniline nanofibrous architecture using electrosynthesis method for supercapacitor application. Curr. Appl. Phys. 2010, 10, 904-909. [CrossRef]

67. Ismail, Y.A.; Chang, J.; Shin, S.R.; Mane, R.S.; Han, S.-H.; Kim, S.J. Hydrogel-Assisted Polyaniline Microfiber as Controllable Electrochemical Actuatable Supercapacitor. J. Electrochem Soc. 2009, 156, A313-A317. [CrossRef]

68. Bélanger, D.; Ren, X.; Davey, J.; Uribe, F.; Gottesfeld, S. Characterization and Long-Term Performance of Polyaniline-Based Electrochemical Capacitors. J. Electrochem. Soc. 2000, 147, 2923-2929. [CrossRef]

69. Otrokhov, G.; Pankratov, D.; Shumakovich, G.; Khlupova, M.; Zeifman, Y.; Vasil'eva, I.; Morozova, O.; Yaropolov, A. Enzymatic synthesis of polyaniline/multi-walled carbon nanotube composite with core shell structure and its electrochemical characterization for supercapacitor application. Electrochim. Acta 2014, 123, 151-157. [CrossRef]

70. Zhou, S.; Mo, S.; Zou, W.; Jiang, F.; Zhou, T.; Yuan, D. Preparation of polyaniline/2-dimensional hexagonal mesoporous carbon composite for supercapacitor. Synth. Met. 2011, 161, 1623-1628. [CrossRef]

71. Jang, J.; Bae, J.; Choi, M.; Yoon, S.-H. Fabrication and characterization of polyaniline coated carbon nanofiber for supercapacitor. Carbon 2005, 43, 2730-2736. [CrossRef]

72. Zhang, Q.; Li, Y.; Feng, Y.; Feng, W. Electropolymerization of graphene oxide/polyaniline composite for high-performance supercapacitor. Electrochim. Acta 2013, 90, 95-100. [CrossRef]

73. Xia, X.; Hao, Q.; Lei, W.; Wang, W.; Sun, D.; Wang, X. Nanostructured ternary composites of graphene $/ \mathrm{Fe}_{2} \mathrm{O}_{3}$ / polyaniline for high-performance supercapacitors. J. Mater. Chem. 2012, 22, 16844-16850. [CrossRef]

(C) 2018 by the authors. Licensee MDPI, Basel, Switzerland. This article is an open access article distributed under the terms and conditions of the Creative Commons Attribution (CC BY) license (http://creativecommons.org/licenses/by/4.0/). 